\title{
Characterization of Adult-Type IgA Vasculitis (Henoch-Schönlein Purpura): A Retrospective Study of 122 Cases
}

\author{
Katsuhiro Hitomi*, Seiichi Izaki, Yuichi Teraki, Yuko Aso, Megumi Yokoyama, Saori Takamura, \\ Yumiko Inoue and Yoshiki Sato
}

Department of Dermatology, Saitama Medical Center, Saitama Medical University, Kawagoe, Saitama, Japan

\begin{abstract}
The clinical features of adult-type $\operatorname{IgA}$ vasculitis have not been well characterized. To analyze the characteristics of IgA vasculitis in adults, patients diagnosed with IgA vasculitis based on EULAR/PRINTO/PRES criteria (2012) in our institution between 2003 and 2012 were studied, comprising 85 adults (age $\geq 21$ years) and 37 pediatric patients ( $\leq 20$ years). Compared with pediatric cases, adult disease showed significantly higher serum C-reactive protein and $\operatorname{IgA}$ values, a lower percentage of cases was associated with infections $(56.5 \%$ vs $89.2 \%, P<0.001)$ but there was a greater range of infections affecting different tissues and organs, and there was occasional cases with malignancy $(8.2 \%)$ including four cases of lung carcinoma and three with hematological disorders. The skin lesions in adults tended to be widely distributed on the abdomen and waist $(15.3 \%$ vs $2.7 \%, P=0.045)$. Adult cases were associated with greater renal involvement, as evidenced by proteinuria, hematuria and/or urinary casts, compared with the pediatric group $(76.2 \% v s$ $48.6 \%, P=0.003)$ and disease recalcitrance was also significantly higher $(38.8 \% v s 18.9 \%, P=0.031)$. Examination of the serum levels of immunoglobulins in adults showed that a sole increase in IgA was associated with renal and gastrointestinal manifestations, but this was not seen in cases with concurrent increases of $\operatorname{IgA}$ and $\operatorname{IgG}$ or $\operatorname{IgA}$, IgG and IgM. Although the retrospective nature of the study is a limitation, it identified possible associations with the wide range of infections, more severe renal damage, and malignancy in adult IgA vasculitis.
\end{abstract}

Keywords: Adult, anaphylactoid purpura, Henoch-Schönlein purpura, immunoglobulin A, malignancy, renal damage, vasculitis.

\section{INTRODUCTION}

Henoch-Schönlein purpura (HSP) and anaphylactoid purpura was renamed immunoglobulin A (IgA) vasculitis in the 2012 revised International Chapel Hill Consensus Conference Nomenclature of Vasculitides [1]. Immune complexes of IgA and unidentified antigens are thought to be pathogenic in this condition [2], and immunofluorescence studies demonstrate deposition of IgA on the vessel walls. Skin involvement manifests as palpable purpura due to the extravasation of cellular and liquid components of the blood from inflamed dermal vessels. Vascular damage is caused by activation of the complement cascade that results in the production of complement membrane attack complex [3], and proteolytic enzymes and oxidants released by neutrophils. Previously, we proposed that the interrupted apoptosis of neutrophils leads to vascular damage in leukocytoclastic vasculitis (LCV), based on ultramicroscopic immunolabeling findings [4]. IgA immune complexes also contribute to nephritis [5] and gastrointestinal symptoms [6]. Arthralgia and arthritis also occur in this disease.

IgA vasculitis primarily affects the pediatric population $[7,8]$. The diagnostic criteria established by the American

*Address correspondence to this author at the Department of Dermatology, Saitama Medical Center, Saitama Medical University, 1981 Kamoda, Kawagoe, Saitama 350-8550, Japan; Tel: +81-49-228-3652; Fax: +81-49-223-3766; E-mail: k-hitomi@js4.so-net.ne.jp
College of Rheumatology (ACR) in 1990 include patient age $\leq$ 20 years as one of its four criteria [9]. Typically, the onset of disease in pediatric patients is preceded by an upper respiratory infection [8]. IgA vasculitis is known to occur in adult and elderly patients with similar manifestations, but the adult disease has not been fully characterized. Blanco et al. [10] in 1997 summarized 46 adult ( $>20$ years) cases compared with 116 cases in children ( $\leq 20$ years), reporting that renal involvement and joint symptoms are more common in adult cases with a lower occurrence of abdominal pain and fever. Tancrede-Bohin et al. [11] investigated predictive factors for renal involvement in adult patients and showed that a recent history of infection, pyrexia, the spread of purpura to the trunk, and elevated biological markers of inflammation are predictive factors for IgA glomerulonephritis. García-Porrúa et al. [12] reported that renal insufficiency is more frequent in adults ( $>20$ years) than in children (< 14 years). Diehl et al. [13] described IgA vasculitis in eight elderly patients aged between 64-85 years and concluded that renal involvement is relatively common and more severe in the elderly. From their experience of three adult cases of $\operatorname{IgA}$ vasculitis associated with malignancy and their review of 31 similar cases in the literature, Zurada et al. [14] suggested that IgA vasculitis may be associated with malignancy and that malignancy may cause IgA vasculitis in adults.

In this study, the clinical features of $\operatorname{IgA}$ vasculitis in adult patients were characterized, and compared with those in pediatric patients. 


\section{METHODS}

The departmental records of patients diagnosed with IgA vasculitis in our institution between 2003 and 2012 were retrospectively analyzed. This study was approved by the Institutional Review Board of Saitama Medical Center (No. 696) in February 2013. Patients were separated into two groups based on the ACR age-related IgA vasculitis diagnostic criterion [9]: pediatric ( $\leq 20$ years) and adult $(\geq$ 21 years) groups. The accuracy of the diagnosis of all cases was reviewed against the criteria of the European League Against Rheumatism/Paediatric Rheumatology International Trials Organisation/Paediatric Rheumatology European Society (EULAR/PRINTO/PRES) [15], which requires the presence of purpura or petechiae predominantly on the lower limbs, plus one of the following features: 1) abdominal pain, 2) LCV or proliferative glomerulonephritis with IgAdominant deposits, 3) arthritis or arthralgia, or 4) proteinuria, hematuria or urinary casts. Furthermore, evidence of $\operatorname{IgA}$ deposition in immunofluorescence studies of skin biopsies was required for the diagnosis in the adult group but this was not strictly applied in the pediatric group because of the relatively low biopsy rate in this group. Of 187 cases (144 and 43 in the adult and pediatric groups, respectively), 122 were studied in detail, consisting of 85 and 37 in the adult and pediatric groups, respectively. The number of patients in the pediatric group was low, since pediatric patients who voluntarily consulted the pediatricians in the same hospital were not involved in the present analysis.

The clinical features of IgA vasculitis, association with infection and malignancy, clinical course, laboratory parameters and histological findings were compared between the pediatric and adult groups. Fisher's exact test and Student's t-test were used for statistical analysis.

\section{RESULTS}

\section{Patient Characteristics}

Fig. (1) shows the age distribution of patients in the study. The mean ages ( \pm S.D.) of the pediatric and adult groups were $9.8 \pm 5.0$ years and $51.7 \pm 17.4$ years, respectively (Table 1), and the male-to-female ratio was 1.18 and 1.24 , respectively, with a slight male predominance in both groups. All adult patients (100\% [85/85]) had IgA deposition in the biopsied skin lesions. Although the number of biopsies was relatively low $(37.8 \%$ [14/37]) in the pediatric group, IgA positivity was high $(100 \%$ [14/14]). The mean values ( \pm S.D.) of serum $C$-reactive protein (CRP) $(2.62 \pm 3.73 \mathrm{mg} / \mathrm{dl}$ in adults $v s 0.92 \pm 0.99 \mathrm{mg} / \mathrm{dl}$ in pediatric group; $P<0.001)$ and $\mathrm{IgA}(405.1 \pm 129.6 \mathrm{mg} / \mathrm{dl}$ vs $232.5 \pm$ $89.1 \mathrm{mg} / \mathrm{dl}$, respectively; $P<0.001)$ were higher in adult than in the pediatric group.

\section{Association with Infection and Malignancy}

As shown in Table 2, signs/symptoms of infection were significantly lower in the adult group than those in the pediatric group $(56.5 \%$ [48/85] vs $89.2 \%$ [33/37], $P<0.001)$. The presence of elevated levels of anti-streptolysin O (ASO) and/or anti-streptokinase (ASK) antibodies was consistently lower in the adult group compared with the pediatric group (25.4\% [18/71] vs 47.1\% [16/34], $P=0.026)$. Throat bacterial cultures were less likely to be positive in the adult

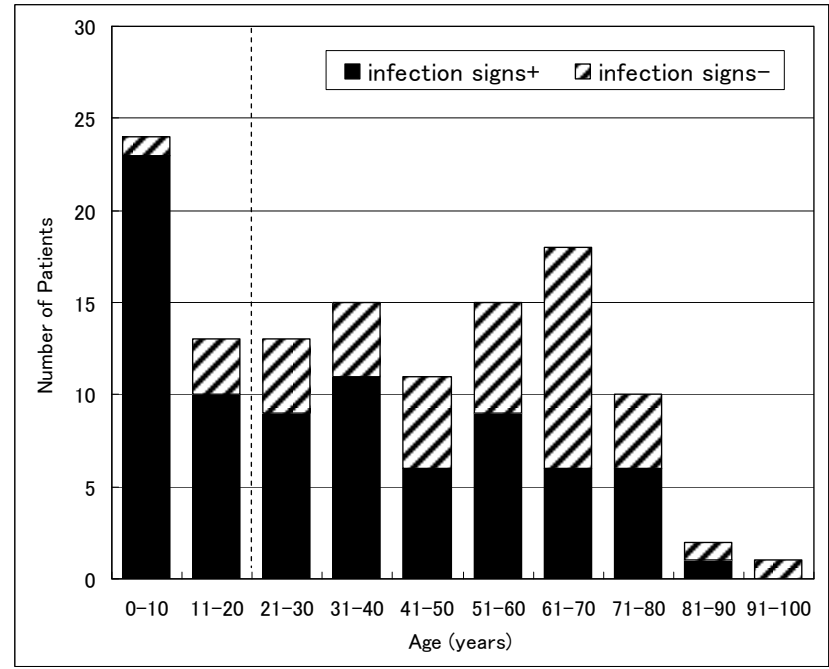

Fig. (1). The age distribution of patients with IgA vasculitis, with and without signs of infection. Patients were separated into ten age groups as shown on the abscissa. Patients presenting with signs of infection are represented by solid bars and those without signs of infection by hatched bars.

Table 1. Patient characteristics and laboratory data.

\begin{tabular}{|c|c|c|c|c|}
\hline & & Age $\leq 20$ & Age $\geq 21$ & \multirow{2}{*}{$\boldsymbol{P}$} \\
\hline & & $(n=37)$ & $(\mathbf{n}=\mathbf{8 5})$ & \\
\hline \multirow[t]{2}{*}{ Sex } & & & & \\
\hline & Male: Female & 20: 17 & $47: 38$ & 0.899 \\
\hline \multirow[t]{3}{*}{ Age (years) } & & & & \\
\hline & Mean \pm SD & $9.8 \pm 5.0$ & $51.7 \pm 17.4$ & \\
\hline & Range & $4-20$ & $21-91$ & \\
\hline \multirow[t]{3}{*}{ Biopsy } & & & & \\
\hline & Performed & $14 / 37(37.8)$ & 85/85 (100) & \\
\hline & IgA positivity & $14 / 14(100)$ & $85 / 85(100)$ & \\
\hline \multirow[t]{4}{*}{ Serum levels } & CRP (mg/dl) & $0.92 \pm 0.99$ & $2.62 \pm 3.73$ & $<0.001 * *$ \\
\hline & & $(0-4.1)$ & $(0-24.7)$ & \\
\hline & $\operatorname{IgA}(\mathrm{mg} / \mathrm{dl})$ & $232.5 \pm 89.1$ & $405.1 \pm 129.6$ & $<0.001^{* *}$ \\
\hline & & $(56.8-445.7)$ & $(155.0-785.2)$ & \\
\hline
\end{tabular}

group than in the pediatric group (45.3\% [24/53] vs $74.2 \%$ $[23 / 31], P=0.010)$. The percentage of positive cultures for Staphylococcus aureus and Streptococcus species was not significantly different between the two groups, while Haemophilus influenzae was significantly less common in the adult group than in the pediatric group $(4.2 \%[1 / 24]$ vs $30.4 \%$ [7/23], $P=0.017)$. A range of infections were present in the preceding four weeks or at the time of diagnosis of IgA vasculitis in the adult group, including pneumonia $(\mathrm{n}=$ $1)$, pyelonephritis $(n=1)$, epididymitis $(n=1)$, cellulitis $(n=$ 1) and fever of unknown origin $(n=3)$; these preceding or concurrent infections were not observed in the pediatric group except for one case of fever of unknown origin. In addition, palmoplantar pustulosis and acrodermatitis 
Table 2. Infection and malignancy associated with IgA vasculitis.

\begin{tabular}{|c|c|c|c|c|c|}
\hline & \multirow{2}{*}{\multicolumn{2}{|c|}{$\begin{array}{c}\text { Age } \leq 20 \\
(n=37)\end{array}$}} & \multirow{2}{*}{\multicolumn{2}{|c|}{$\begin{array}{c}\text { Age } \geq 21 \\
(n=85)\end{array}$}} & \multirow{3}{*}{$\boldsymbol{P}$} \\
\hline & & & & & \\
\hline & $\mathbf{n}$ & $(\%)$ & $\mathbf{n}$ & $(\%)$ & \\
\hline Recent signs of infection ${ }^{1}$ & $33 / 37$ & $(89.2)$ & $48 / 85$ & $(56.5)$ & $<0.001^{* *}$ \\
\hline \multicolumn{6}{|l|}{ Questionnaire } \\
\hline Recent symptoms of infection & $19 / 37$ & $(51.4)$ & $29 / 85$ & $(34.1)$ & 0.073 \\
\hline Upper respiratory infection & $18 / 19$ & $(94.7)$ & $22 / 29$ & $(75.9)$ & 0.086 \\
\hline Others & $1 / 19$ & $(5.3)$ & $7 / 29$ & $(24.1)$ & 0.086 \\
\hline \multicolumn{6}{|l|}{ Laboratory examination } \\
\hline Increased serum levels of & & & & & \\
\hline $\mathrm{ASO}^{2}$ and/or ASK & $16 / 34$ & $(47.1)$ & $18 / 71$ & $(25.4)$ & $0.026^{*}$ \\
\hline Throat bacterial culture positivity & $23 / 31$ & $(74.2)$ & $24 / 53$ & $(45.3)$ & $0.010^{* *}$ \\
\hline \multicolumn{6}{|l|}{ Bacterial strains } \\
\hline$M S S A^{3}$ & $12 / 23$ & $(52.2)$ & $12 / 24$ & $(50.0)$ & 0.882 \\
\hline$M R S A^{4}$ & $1 / 23$ & $(4.3)$ & $2 / 24$ & $(8.3)$ & 0.576 \\
\hline Haemophilus influenzae & $7 / 23$ & $(30.4)$ & $1 / 24$ & $(4.2)$ & $0.017^{* *}$ \\
\hline Streptococcus spp. & $6 / 23$ & $(26.1)$ & $11 / 24$ & $(45.8)$ & 0.159 \\
\hline Others & $3 / 23$ & $(13.0)$ & $2 / 24$ & $(8.3)$ & 0.601 \\
\hline Association of malignancy & $0 / 37$ & $(0)$ & $7 / 85$ & $(8.2)$ & 0.072 \\
\hline MALT $^{5}$ lymphoma & 0 & $(0)$ & $1 / 7$ & $(14.3)$ & \\
\hline Multiple myeloma & 0 & $(0)$ & $1 / 7$ & $(14.3)$ & \\
\hline Myelodysplastic syndrome & 0 & $(0)$ & $1 / 7$ & $(14.3)$ & \\
\hline Lung carcinoma & 0 & $(0)$ & $4 / 7$ & $(57.1)$ & \\
\hline
\end{tabular}

${ }^{1}$ Signs of infection include fever, sore throat, cough, redness, swelling and tenderness.

${ }^{2}$ Reference levels: ASO, 0-140 (IU/ml) and ASK, less than $\times 320$.

${ }^{3}$ Methicillin-sensitive Staphylococcus aureus.

${ }^{4}$ Methicillin-resistant Staphylococcus aureus.

${ }^{5}$ Mucosa-associated lymphoid tissue.

$* P<0.05, * * P<0.02$.

continua of Hallopeau affected two adult patients with $\operatorname{IgA}$ vasculitis.

Notably, in 7 of 85 adult patients $(8.2 \%)$, malignancies were found at presentation, during hospitalization or in the follow-up period $(18.1 \pm 25.8$ months $[$ mean $\pm \mathrm{SD}])$. These included four cases of advanced lung carcinoma $(n=4$; two cases with stage IV adenocarcinoma, one with stage III small cell carcinoma and one with stage IV squamous cell carcinoma), and hematological malignancies including myelodysplastic syndrome $(\mathrm{n}=1)$, mucosa-associated lymphoid tissue (MALT) lymphoma $(\mathrm{n}=1)$, and multiple myeloma $(n=1)$. The patient with MALT lymphoma was 36 years old, while other patients with malignancies were $\geq 56$ years of age. Serum IgA levels of four adult patients with lung carcinoma were higher than adult patients without malignancy $(613.5 \pm 86.2 \mathrm{mg} / \mathrm{dl}$ vs $394.1 \pm 126.0 \mathrm{mg} / \mathrm{dl}, P=$ 0.038). With persistent cough as an initial symptom, two lung carcinomas were found during hospitalization of $\operatorname{IgA}$ vasculitis patients. In patients with MALT lymphoma and multiple myeloma, IgA vasculitis repeatedly improved and relapsed, associated with the state of malignancy. However, regardless of the presence or absence of malignancy, there was no significant difference in other clinical features and laboratory data. Malignancies in the pediatric group were not found at presentation and during the follow-up period $(6.1 \pm$ 6.3 months).

\section{Distribution Pattern of Purpura and Morphology of Skin Lesions}

All patients in both groups had palpable purpura on the lower extremities (Table 3). Lesions on the abdomen and waist were statistically more common in the adult group than in the pediatric group $(15.3 \%$ [13/85] vs 2.7\% [1/37], $P=$ $0.045)$. Hemorrhagic bullae and erosions more commonly affected adult than pediatric patients (14.1\% [12/85] vs 5.4\% $[2 / 37])$, but this was statistically insignificant $(P=0.165)$.

\section{Renal, Gastrointestinal and Joint Manifestations}

The proportion of patients with signs of renal manifestations was higher in the adult group compared with the pediatric group $(76.2 \%$ [64/84] vs $48.6 \%$ [18/37], $P=$ $0.003)$. Compared with pediatric patients, a significantly higher proportion of adult patients had proteinuria $(52.4 \%$ [44/84] vs 27.0\% [10/37], $P=0.010)$ and hematuria $(56.0 \%$ [47/84] vs 29.7\% [11/37], $P=0.008$ ) (Table 3). Furthermore, urinary casts including granular, waxy, fatty, red blood cell, 
Table 3. Cutaneous signs and renal, gastrointestinal and joint manifestations in IgA vasculitis.

\begin{tabular}{|c|c|c|c|c|c|}
\hline \multirow{2}{*}{ Clinical Manifestations } & \multicolumn{2}{|c|}{$\begin{array}{c}\text { Age } \leq 20 \\
(n=37)\end{array}$} & \multicolumn{2}{|c|}{$\begin{array}{c}\text { Age } \geq 21 \\
(n=85)\end{array}$} & \multirow{2}{*}{$P$} \\
\hline & $\mathbf{n}$ & $(\%)$ & $\mathbf{n}$ & $(\%)$ & \\
\hline Purpura & $37 / 37$ & $(100)$ & $85 / 85$ & $(100)$ & - \\
\hline \multicolumn{6}{|l|}{ Distribution } \\
\hline Abdomen/waist & $1 / 37$ & $(2.7)$ & $13 / 85$ & $(15.3)$ & $0.045^{*}$ \\
\hline Genital area/buttocks & $8 / 37$ & $(21.6)$ & $13 / 85$ & $(15.3)$ & 0.395 \\
\hline Upper extremities & $14 / 37$ & $(37.8)$ & $38 / 85$ & $(44.7)$ & 0.481 \\
\hline Lower limbs & $37 / 37$ & $(100)$ & $85 / 85$ & $(100)$ & - \\
\hline Proteinuria & $10 / 37$ & $(27.0)$ & $44 / 84$ & $(52.4)$ & $0.010 * *$ \\
\hline Hematuria & $11 / 37$ & $(29.7)$ & $47 / 84$ & $(56.0)$ & $0.008 * *$ \\
\hline \multicolumn{6}{|l|}{ Abnormal urinary sediment } \\
\hline Urinary casts ${ }^{1}$ & $13 / 37$ & $(35.1)$ & $60 / 84$ & $(71.4)$ & $<0.001^{* *}$ \\
\hline Red blood cell deformity & $4 / 37$ & $(10.8)$ & $20 / 84$ & $(23.8)$ & 0.099 \\
\hline Renal biopsy & $1 / 37$ & $(2.7)$ & $8 / 84$ & $(9.5)$ & 0.188 \\
\hline Gastrointestinal symptoms & $12 / 36$ & $(33.3)$ & $38 / 84$ & $(45.2)$ & 0.270 \\
\hline Abdominal pain & $12 / 36$ & $(33.3)$ & $36 / 84$ & $(42.9)$ & 0.329 \\
\hline Ankle & $13 / 36$ & $(36.1)$ & $20 / 84$ & $(23.8)$ & 0.167 \\
\hline Hip & 0 & (0) & $2 / 84$ & (2.4) & 0.350 \\
\hline Shoulder & 0 & (0) & $1 / 84$ & $(1.2)$ & 0.511 \\
\hline Finger & 0 & (0) & $3 / 84$ & (3.6) & 0.251 \\
\hline Toe & 0 & (0) & $2 / 84$ & (2.4) & 0.350 \\
\hline Not described & 0 & (0) & $1 / 84$ & $(1.2)$ & - \\
\hline
\end{tabular}

${ }^{1}$ Urinary casts include granular, waxy, fatty, red blood cell, white blood cell and epithelial cell casts but not hyaline casts.

$* P<0.05, * * P<0.02$.

white blood cell and epithelial cell casts but not hyaline casts were more frequently found in adults than in pediatric patients $(71.4 \%$ [60/84] vs 35.1\% [13/37], $P<0.001)$. The presence of red blood cell deformity was not significantly different between the two groups. Severe renal disease requiring a renal biopsy occurred in eight cases in the adult group (one case had rapidly progressive glomerulonephritis), but only one renal biopsy was performed in the pediatric group. Gastrointestinal symptoms were present in $45.2 \%$ $(38 / 84)$ and $33.3 \%(12 / 36)$ of patients in the adult and pediatric groups, respectively, but the difference was statistically insignificant $(P=0.270)$. Arthralgia affected more than half $(52.8 \%$ [19/36]) of the pediatric patients.
Although this was relatively less in the adult group $(39.3 \%$ [33/84], $P=0.172$ ), various joints including the hip, shoulders, fingers and toes were affected.

\section{Therapy and Outcome}

Table 4 shows the admission rate, use of prednisolone, antibiotics and dapsone, and clinical outcome. Admission was recommended when patients had renal, abdominal or joint manifestations in addition to skin lesions. More than two thirds of adult patients were hospitalized for treatment and bed rest. The rate of admission was significantly higher in the adult group than in the pediatric group $(68.2 \%$ [58/85] 
Table 4. Admission rate, medical therapy and outcome of IgA vasculitis.

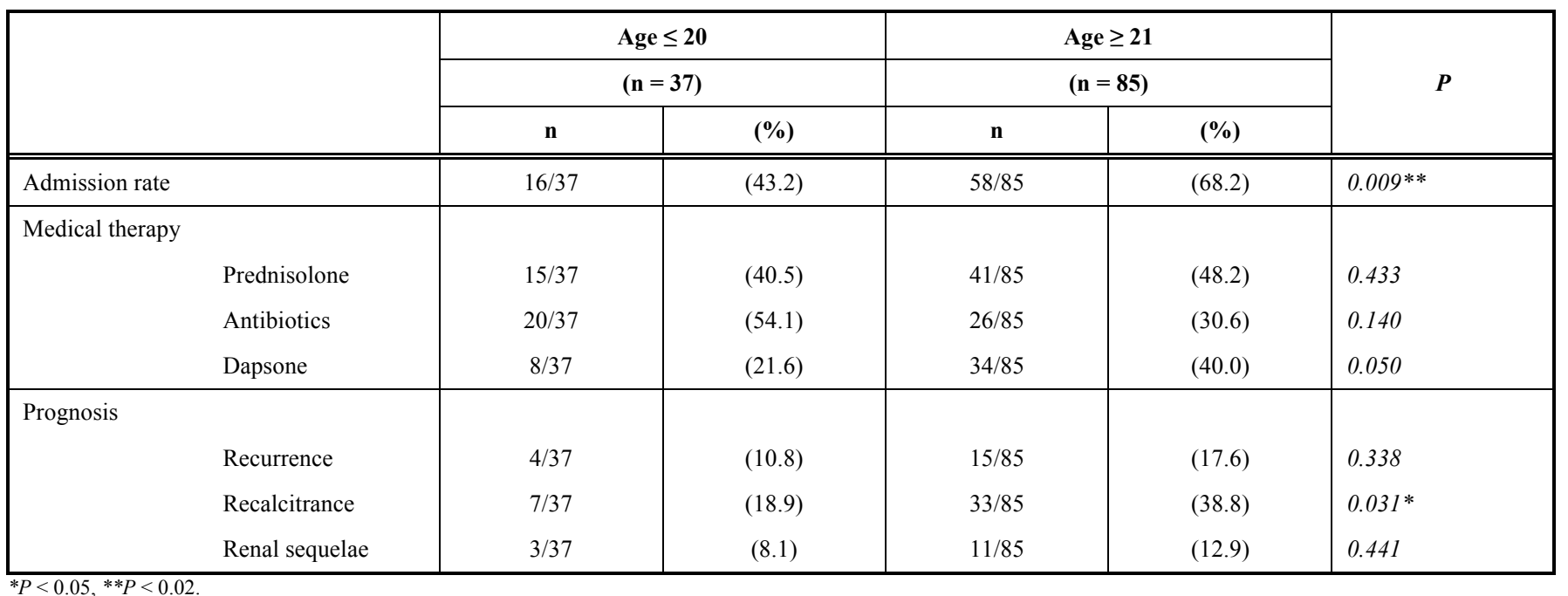

vs 43.2\% [16/37], $P=0.009$ ). Prednisolone was given to approximately half of adult patients, which was higher than that in the pediatric group, but the difference was insignificant (48.2\% [41/85] vs 40.5\% [15/37], $P=0.433)$. Antibiotic use was greater in the pediatric group $(54.1 \%$ [20/37]), which may reflect the association of IgA vasculitis with infection. Dapsone was sometimes used to treat adult patients (40.0\% [34/85]). Recurrence of skin lesions and/or other manifestations one month or more after initial resolution was more common in the adult group, but the difference was insignificant (17.6\% [15/85] vs 10.8\% [4/37], $P=0.338)$. Recalcitrant cases that did not show improvement despite treatment for more than one month were more common in the adult group compared with the pediatric group $(38.8 \%$ [33/85] vs $18.9 \%$ [7/37], $P=0.031)$. Eleven adults $(12.9 \%$ [11/85]) and three teens $(8.1 \%[3 / 37])$ had renal sequelae. Because of persistent proteinuria $(n=8)$ and/or hematuria $(n=12)$, they still needed outpatient nephrology care on December 2013. But the renal disease did not lead to chronic renal failure.

Aggressive medical therapy consisting of steroid pulse therapy, half-dose pulse steroid therapy and/or immunosuppressants such as cyclophosphamide, mizoribine or cyclosporine was required for renal disease in five adult patients, whereas such therapy was not required in the pediatric group. With respect to severe gastrointestinal involvement, a 29-year-old male patient required oral prednisolone and factor XIII infusion. He had complained of an uncomfortable feeling in the abdomen, and had decreased plasma factor XIII activity (41\%) that was below the lower limit of $70 \%$. Another 64-year-old male patient had severe abdominal pain, bloody diarrhea and rapidly progressive anemia. His factor XIII activity was 46\%. Upper gastrointestinal endoscopy showed multiple duodenal ulcers. Intravenous infusion of prednisolone at $60 \mathrm{mg} / \mathrm{day}$ completely resolved those abdominal involvements except for decreased factor XIII activity. However, during tapering of prednisolone to $40 \mathrm{mg} /$ day, he had sudden severe bloody stools followed by acute respiratory distress syndrome. The jejunal artery bleeding was found on angiography. Unfortunately, the patient died six months after disease onset because of peritonitis despite aggressive therapy including partial jejunectomy. Although factor XIII activity was not always examined in our hospital, there were significant differences in the prevalence of gastrointestinal involvement between normal or high factor XIII activity $(\geq 70 \%)$ and low activity groups $(<70 \%)(44.4 \%$ [8/18] vs $100 \%$ [8/8], $P=$ $0.007)$ in adults. In contrast, all pediatric patients had an uneventful recovery.

\section{Relationship Between Renal Involvement and Other Clinical Characteristics in the Adult Group}

Adult patients with IgA vasculitis were separated into those with and without renal involvement, which was indicated by the presence of proteinuria, hematuria and/or urinary casts, for further analysis (Table 5). The proportion of patients suffering from purpura on the trunk and upper extremities was significantly greater in the renal disease group than in the group without renal disease (59.4\% [38/64] vs $20.0 \%$ [4/20], $P=0.002$ ). Hemorrhagic bullous lesions and/or erosions were observed in $20.3 \%$ (13/64) of the patients with renal manifestations, whereas no such lesions were observed in those without renal manifestations $(P=$ $0.028)$. Gastrointestinal symptoms were more common in adult patients with renal disease than those without renal disease (48.4\% [31/64] vs 30.0\% [6/20]), but the difference was statistically insignificant $(P=0.147)$. Arthralgia was seen in approximately $40 \%$ of patients in both groups. Adult patients with IgA vasculitis and renal involvement had higher rates of hospitalization than those without renal disease (76.6\% [49/64] vs 45.0\% [9/20], $P=0.008)$. Disease recurrence was similar in both groups, while occurrence of recalcitrant disease was higher in the renal disease group compared with the group without renal disease $(45.3 \%$ [29/64] vs 20.0\% [4/20], $P=0.043)$.

\section{Serum Immunoglobulin Levels and Clinical Manife- stations in Adult IgA Vasculitis}

Table 5 shows that serum IgA levels in adult patients exceeded the normal range (140.0-240.0 $\mathrm{mg} / \mathrm{dl})$ but no significant difference was observed between those with renal disease and those without renal disease $(410.1 \pm 124.0 \mathrm{mg} / \mathrm{dl}$ vs $385.3 \pm 150.3 \mathrm{mg} / \mathrm{dl}, P=0.531)$. Immunoglobulin levels were also compared between groups of adult patients with 
Table 5. Renal manifestations in adult cases of $\operatorname{IgA}$ vasculitis.

\begin{tabular}{|c|c|c|c|c|c|}
\hline & \multirow{2}{*}{\multicolumn{2}{|c|}{$\begin{array}{c}\text { Renal Manifestations } \\
+ \\
(n=64)\end{array}$}} & \multirow{2}{*}{\multicolumn{2}{|c|}{$\begin{array}{c}\text { Renal Manifestations } \\
- \\
(n=20) \\
\end{array}$}} & \multirow{3}{*}{$P$} \\
\hline & & & & & \\
\hline & $\mathbf{n}$ & $(\%)$ & $\mathbf{n}$ & $(\%)$ & \\
\hline \multicolumn{6}{|l|}{ Sex } \\
\hline Male:Female & \multicolumn{2}{|c|}{$34: 30(1.13: 1)$} & \multicolumn{2}{|c|}{$13: 7(1.86: 1)$} & 0.350 \\
\hline \multicolumn{6}{|l|}{ Age (years) } \\
\hline Mean \pm SD & \multirow{2}{*}{\multicolumn{2}{|c|}{$\begin{array}{c}52.4 \pm 16.4 \\
21-83\end{array}$}} & \multirow{2}{*}{\multicolumn{2}{|c|}{$\begin{array}{c}48.9 \pm 21.0 \\
24-91\end{array}$}} & 0.495 \\
\hline Range & & & & & \\
\hline Recent signs of infection & $33 / 64$ & $(51.6)$ & $14 / 20$ & $(70.0)$ & 0.147 \\
\hline Serum IgA level $(\mathrm{mg} / \mathrm{dl})^{2}$ & \multicolumn{2}{|c|}{$410.1 \pm 124.0$} & \multicolumn{2}{|c|}{$385.3 \pm 150.3$} & 0.531 \\
\hline \multicolumn{6}{|l|}{ Clinical manifestations } \\
\hline \multicolumn{6}{|l|}{ Purpura } \\
\hline Distributed on the trunk and/or upper extremities & $38 / 64$ & $(59.4)$ & $4 / 20$ & $(20.0)$ & $0.002 * *$ \\
\hline Hemorrhagic bullous lesions/erosions & $13 / 64$ & $(20.3)$ & $0 / 20$ & $(0.0)$ & $0.028 *$ \\
\hline Gastrointestinal symptoms $^{3}$ & $31 / 64$ & $(48.4)$ & $6 / 20$ & $(30.0)$ & 0.147 \\
\hline Arthralgia & $24 / 64$ & $(37.5)$ & $8 / 20$ & $(40.0)$ & 0.841 \\
\hline Admission rate & $49 / 64$ & $(76.6)$ & $9 / 20$ & $(45.0)$ & $0.008 * *$ \\
\hline \multicolumn{6}{|l|}{ Medical therapy } \\
\hline Prednisolone & $31 / 64$ & $(48.4)$ & $10 / 20$ & $(50.0)$ & 0.903 \\
\hline Antibiotics & $18 / 64$ & $(28.1)$ & $8 / 20$ & $(40.0)$ & 0.316 \\
\hline Dapsone & $28 / 64$ & $(43.8)$ & $6 / 20$ & $(30.0)$ & 0.274 \\
\hline \multicolumn{6}{|l|}{ Outcome } \\
\hline Recurrence & $10 / 64$ & $(15.6)$ & $5 / 20$ & $(25.0)$ & 0.339 \\
\hline Recalcitrance & $29 / 64$ & $(45.3)$ & $4 / 20$ & $(20.0)$ & $0.043 *$ \\
\hline
\end{tabular}

${ }^{1}$ Proteinuria, hematuria and/or urinary casts

${ }^{2}$ Normal range of IgA $(140.0-240.0 \mathrm{mg} / \mathrm{dl})$.

${ }^{3}$ Abdominal pain, hematochezia and/or fecal occult blood.

$* P<0.05, * * P<0.02$.

and without gastrointestinal and joint involvement (Fig. 2). It was noted that $\operatorname{IgG}$ and $\operatorname{IgA}$ levels were significantly lower in patients with gastrointestinal involvement than those without gastrointestinal symptoms $(P<0.05)$, and a similar tendency was observed in patients with joint manifestations for all immunoglobulin levels. Furthermore, as shown in Table 6, we compared the incidence of renal, gastrointestinal and joint manifestations in patients with elevated levels of immunoglobulins, and found that the 32 patients with a sole increase in IgA level had a higher incidence of renal $(87.5 \%$ [28/32]) and gastrointestinal (59.4\% [19/32]) involvement. This was in contrast to the net incidence of renal $(65.1 \%$ [28/43], $P=0.027)$ and gastrointestinal $(34.9 \%$ [15/43], $P=$ $0.035)$ manifestations in the other groups. However, a lower proportion of patients with concurrent elevation of IgA and $\mathrm{IgG}$, or IgA, IgG and IgM had gastrointestinal manifestations (11.9\% [3/14], $P=0.046$; and $0 \%[0 / 8], P=0.006$; respectively).

\section{DISCUSSION}

The present study showed that adult-type $\operatorname{IgA}$ vasculitis is different from pediatric-type IgA vasculitis. Preceding upper respiratory infections were relatively less common in

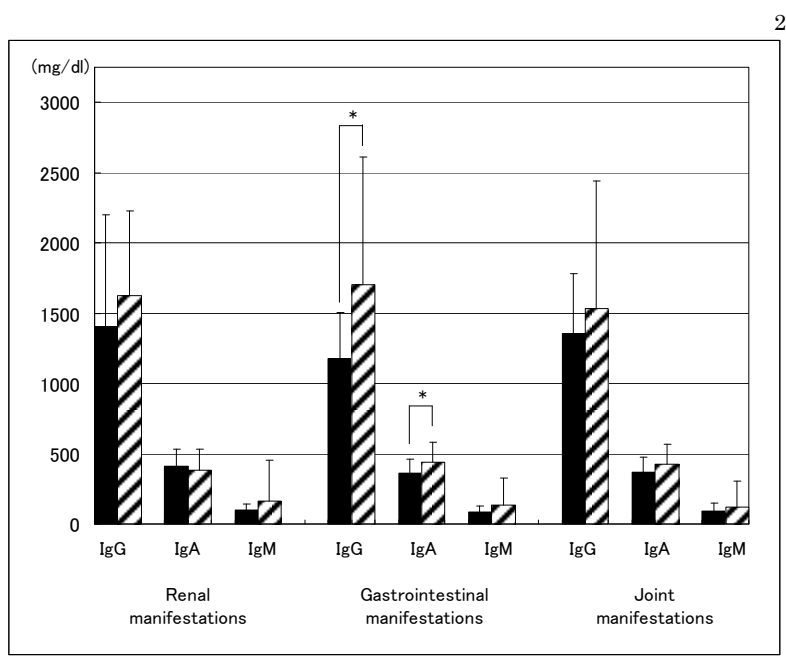

Fig. (2). Comparison of serum IgG, IgA and IgM levels in adult patients with and without renal, gastrointestinal and joint manifestations. Solid bars represent patients with the clinical manifestation and hatched bars represent those without the manifestation. Immunoglobulin levels are expressed as mean \pm SD. $* P<0.05$. 
Table 6. Patients with increased serum immunoglobulin levels and clinical manifestations in $\operatorname{adult} \operatorname{IgA}$ vasculitis.

\begin{tabular}{|c|c|c|c|c|c|c|c|c|c|c|c|}
\hline \multirow{2}{*}{ Ig Increase $^{1}$} & \multicolumn{2}{|c|}{ No. of Adult Cases } & \multicolumn{3}{|c|}{ Renal Manifestations } & \multicolumn{3}{|c|}{ Gastrointestinal Manifestations } & \multicolumn{3}{|c|}{ Joint Manifestations } \\
\hline & $\mathbf{n}$ & $(\%)$ & $\mathbf{n}$ & $(\%)$ & $P^{2}$ & $\mathbf{n}$ & $(\%)$ & $\boldsymbol{P}$ & $\mathbf{n}$ & $(\%)$ & $\boldsymbol{P}$ \\
\hline IgG only & $1 / 75^{3}$ & (1.3) & $0 / 1^{4}$ & (0) & 0.084 & $0 / 1^{5}$ & (0) & 0.359 & $0 / 1^{6}$ & (0) & 0.411 \\
\hline IgA only & $32 / 75$ & $(42.7)$ & $28 / 32$ & $(87.5)$ & $0.027^{*}$ & $19 / 32$ & $(59.4)$ & $0.035^{*}$ & $13 / 32$ & $(40.6)$ & 0.924 \\
\hline IgM only & $4 / 75$ & $(5.3)$ & $2 / 4$ & $(50.0)$ & 0.244 & $3 / 4$ & $(75.0)$ & 0.221 & $2 / 4$ & $(50.0)$ & 0.675 \\
\hline $\operatorname{IgG}$ and $\operatorname{IgA}$ & $14 / 75$ & $(18.7)$ & $8 / 14$ & $(57.1)$ & 0.095 & $3 / 14$ & $(11.9)$ & $0.046^{*}$ & $5 / 14$ & $(35.7)$ & 0.717 \\
\hline $\operatorname{Ig} \mathrm{A}$ and $\operatorname{IgM}$ & $14 / 75$ & $(18.7)$ & $12 / 14$ & $(85.7)$ & 0.292 & $7 / 14$ & $(50.0)$ & 0.697 & $5 / 14$ & $(35.7)$ & 0.717 \\
\hline $\operatorname{IgG}, \operatorname{IgA}$ and $\operatorname{IgM}$ & $8 / 75$ & $(10.7)$ & $5 / 8$ & $(62.5)$ & 0.403 & $0 / 8$ & (0) & $0.006^{* *}$ & $3 / 8$ & $(37.5)$ & 0.879 \\
\hline All $\mathrm{WNL}^{7}$ & $2 / 75$ & $(2.7)$ & $1 / 2$ & $(50.0)$ & 0.416 & $2 / 2$ & $(100)$ & 0.115 & $2 / 2$ & $(100)$ & 0.079 \\
\hline Total & $75 / 75$ & $(100)$ & $56 / 75$ & (74.7) & & $34 / 75$ & $(45.3)$ & & $30 / 75$ & $(40.0)$ & \\
\hline
\end{tabular}

${ }^{1}$ Patients with an increase of immunoglobulin (Ig) subtypes were grouped as shown in this column. Normal ranges for IgG, IgA and IgM are $850-1,500 \mathrm{mg} / \mathrm{dl}, 140-240 \mathrm{mg} / \mathrm{dl}$, and $40.0-100 \mathrm{mg} / \mathrm{dl}$, respectively.

${ }^{2} P$-value: incidence of renal, gastrointestinal or joint manifestations in specific groups with Ig increase was compared with the incidence of renal, gastrointestinal or joint manifestations in the net number of patients in the other groups i.e., total number of patients minus the number of patients in the specified group.

${ }^{3}$ Number of patients with the specified Ig increase/75 cases who had complete data for all three immunoglobulin levels.

${ }^{4}$ Number of patients with renal manifestations/number of patients with the specified Ig increase.

${ }^{5}$ Number of patients with gastrointestinal manifestations/number of patients with the specified Ig increase.

${ }^{6} \mathrm{Number}$ of patients with joint manifestations/number of patients with the specified Ig increase.

${ }^{7} \mathrm{WNL}$, within normal limits.

$* P<0.05, * * P<0.02$.

adult-type disease $(56.5 \%)$ than in pediatric disease $(89.2 \%)$. However, adult cases were associated with a range of infections, and clinicians should be vigilant for infections such as pneumonia, cellulitis and other infectious foci associated with palmoplantar pustulosis [16] and acrodermatitis continua of Hallopeau.

Our findings revealed that adult-type $\operatorname{IgA}$ vasculitis might be associated with malignancy. This is consistent with the findings described by Zurada et al. [14]. They concluded that lung and prostate carcinomas and hematologic malignancies such as multiple myeloma and non-Hodgkin's lymphoma are the most commonly associated malignancies. In our study, seven cases (8.2\%) of adult-type IgA vasculitis were associated with malignancy: four had lung cancers and the other three had hematological disorders. Six of the seven cases were over 56 years of age, and the malignancies were found at the onset of IgA vasculitis in three of seven cases. Mitsui et al. compared their 53 cases of adult-type IgA vasculitis and reported that the cases with malignancy were significantly older, with a lesser prevalence of arthralgia and a higher erythrocyte sedimentation rate than those without malignancy [17]. In our study, except for the higher serum IgA levels in the patients with advanced lung carcinoma, other examined features were not different between patients with and without malignancy. Two cases of lung carcinoma only had persistent cough. Therefore, we need to be vigilant for solid and hematologic malignancies in adult-type IgA vasculitis in cases over 60 years of age, especially in recalcitrant cases or those without apparent infectious triggers. We did not investigate the causative antigen(s) complexed with IgA in the present study. The cancer-related antigen(s) in comparison with infection-related antigens in IgA vasculitis have not been studied.

Renal disease was more common in the adult group as evidenced by proteinuria, hematuria and/or urinary casts in approximately three quarters $(76.2 \%)$ of adult patients, and tended to be more severe. In an analysis of 100 pediatric cases of IgA vasculitis, Saulsbury [7] concluded that $40 \%$ of patients showed signs of nephritis but the vast majority resolved within nine weeks, except for one case. Similarly, Roberts et al. [8] reported that the majority of renal disease in pediatric patients resolved spontaneously, with $1 \%$ progressing to end-stage renal disease. In contrast, Diehl et al. [13] described eight cases of elderly-onset, IgA-positive HSP requiring corticosteroid therapy. In their six patients with renal disease, three patients required both corticosteroids and immunosuppressants, and one patient with severe renal disease required hemodialysis. In the present study, 8 of 84 cases with renal manifestations required a renal biopsy, and five of them needed more aggressive therapy, but none resulted in renal failure. We agree with the suggestion by Diehl et al. [13] that elderly patients with IgA vasculitis are more vulnerable to severe renal disease compared with pediatric patients.

Gastrointestinal involvement was more common in adulttype IgA vasculitis (45.2\%) compared with pediatric disease (33.3\%). A study of intestinal biopsies showed IgA deposition and LCV affecting the submucosal vessels of the small intestine [18], similar to that seen in the skin. Abdominal pain may precede cutaneous signs [19]. It was noted that one case was associated with fatal jejunal artery bleeding, peritonitis and decreased factor XIII activity. Matayoshi et al. investigated 44 cases of adult-type IgA vasculitis and showed that factor XIII activity reflected the severities of digestive tract and joint disorders, but not renal symptoms [20]. Clinicians should be aware that a similar outcome might occur in severe gastrointestinal disease. We think that the measurement of plasma factor XIII activity, fecal occult blood test and endoscopy would aid the management of patients with abdominal symptoms.

The distribution of skin lesions was different between adult and pediatric IgA vasculitis. Our findings suggest that purpura on the abdomen and/or waist was more frequently observed in adults, and purpura on the trunk and/or upper 
extremities and change into hemorrhagic bulla may be associated with renal involvement. Thus, close observation of the morphology and distribution pattern of the skin lesions may lead to better management of adult IgA vasculitis, since renal involvement in adult and elderly patients should be carefully managed. On the other hand, proteinuria and hematuria should be monitored and routine administration of steroids is not beneficial in pediatric patients [21]. In the present study, dapsone was often used for $\operatorname{IgA}$ vasculitis, especially in adult patients with extensive skin lesions. Dapsone decreases neutrophil chemotaxis and their activity, suppresses the oxidative pathway, and has an antiinflammatory effect in $\operatorname{IgA}$ vasculitis $[22,23]$. We believe that dapsone is useful for adult patients, but care must be taken to avoid possible side effects.

The serum level of IgA was increased in the majority of adult patients with IgA vasculitis, but the increase in serum IgA level did not correlate with renal involvement $(P=$ 0.531). Calvo-Río V et al. reported that increased levels of serum IgA were more commonly observed in the subgroup of patients with nephropathy than in those without renal involvement among HSP patients including children and adults (41.8\% vs 10\%, respectively; $P=0.027$ ) [24]. Our analysis was limited to adult patients because of the relatively low number of cases of children with common $\operatorname{Ig} \mathrm{A}$ vasculitis and the significant difference in serum IgA levels between the adult and pediatric group $(405.1 \pm 129.6 \mathrm{mg} / \mathrm{dl}$ vs $232.5 \pm 89.1 \mathrm{mg} / \mathrm{dl}$, respectively; $P<0.001)$. Further examination of adult patients in our study revealed that a high proportion of patients with sole elevation of $\operatorname{IgA}$ had renal involvement compared with the other groups $(87.5 \% \mathrm{vs}$ $65.1 \%, P=0.027)$. Similarly, gastrointestinal involvement was more common in patients with a sole increase in IgA level $(59.4 \%$ vs $34.9 \%, P=0.035)$, whereas this association was not seen in patients with increased IgA and IgG, or concurrent IgA, IgG and IgM elevation. In children, it has been reported that renal involvement is seen in $32 \%$ of patients with increased $\operatorname{IgA}$, and raised $\operatorname{IgA}$ in association with reduced $\mathrm{IgM}$ levels is predictive of severe complications [25]. This suggests that an unknown interaction exists between circulating $\operatorname{IgA}$ and other immunoglobulins in IgA vasculitis, and may be related to its complications. Lau et al. [5] suggested that anti-glycan IgG and $\operatorname{IgA} 1$ interact to form a complex that reacts to glomerular and mesangial cells in nephritis associated with IgA vasculitis, but the roles of $\operatorname{IgG}$ and $\operatorname{IgM}$ in the pathogenesis of $\operatorname{IgA}$ vasculitis-associated complications remain unknown. Further study of the role of immunoglobulin subtypes in IgA vasculitis is required.

Byun et al. [26] recently suggested that relapse is common in adult IgA vasculitis, and predictive factors for relapse include onset at an older age, persistent rash, abdominal pain, hematuria, and the presence of underlying disease. Poterucha et al. [27] reported that histopathologic markers might predict renal and gastrointestinal involvement, stating that absence of eosinophils and age $>$ 40 years might be important predictors of renal involvement. Our results showed that recalcitrant disease should be carefully monitored because it was significantly more common in the adult group than in the pediatric group (38.8\% vs $18.9 \%, P=0.031)$; specifically, it was more common in adults with renal manifestations than in those without (45.3\% vs $20.0 \%, P=0.043)$. Approximately half of the adult patients were treated with corticosteroids, together with immunosuppressants in some cases.

In summary, we analyzed patients with $\operatorname{IgA}$ vasculitis comprising 35 pediatric and 87 adult patients, and suggest that adult $\operatorname{IgA}$ vasculitis should be managed carefully because of the greater risk of complications, especially renal damage. Furthermore, we should pay attention to the possible association with malignancy. Although statistical analysis did not show significance, and the IgA vasculitis guidelines of the Japanese Dermatological Association [28] and Japanese Circulation Society [29] did not suggest this possibility, we should consider the possible association of malignancy when we see adult IgA vasculitis. Although the retrospective nature of the study is a limitation, this study provides additional insight into adult-type $\operatorname{IgA}$ vasculitis and the information is useful for the management of this condition.

\section{CONFLICT OF INTEREST}

The authors confirm that they have no conflicts of interest.

\section{ACKNOWLEDGEMENTS}

Declared none.

\section{REFERENCES}

[1] Jennette JC, Falk RJ, Bacon PA, et al. 2012 revised International Chapel Hill Consensus Conference Nomenclature of Vasculitides. Arthritis Rheum 2013; 65: 1-11.

[2] Linskey KR, Kroshinsky D, Mihm MC Jr, Hoang MP. Immunoglobulin-A-associated small-vessel vasculitis: a 10-year experience at the Massachusetts General Hospital. J Am Acad Dermatol 2012; 66: 813-22.

[3] Kawana S, Shen GH, Kobayashi Y, Nishiyama S. Membrane attack complex of complement in Henoch-Schönlein purpura skin and nephritis. Arch Dermatol Res 1990; 282: 183-7.

[4] Yamamoto T, Kaburagi Y, Izaki S, Tanaka T, Kitamura K. Leukocytoclasis: ultrastructural in situ nick end labeling study in anaphylactoid purpura. J Dermatol Sci 2000; 24: 158-65.

[5] Lau KK, Suzuki H, Novak J, Wyatt RJ. Pathogenesis of HenochSchönlein purpura nephritis. Pediatr Nephrol 2012; 25: 19-26.

[6] Kato S, Ebina K, Naganuma H, Sato S, Maisawa S, Nakagawa H. Intestinal IgA deposition in Henoch-Schönlein purpura with severe gastro-intestinal manifestations. Eur J Pediatr 1996; 155: 91-5.

[7] Saulsbury FK. Henoch-Schönlein purpura in children. Reports of 100 patients and review of the literature. Medicine 1999; 78: 395 409.

[8] Roberts PF, Waller TA, Brinker TM, Riffe IZ, Sayre JW, Bratton RL. Henoch-Schönlein purpura: a review article. South Med J 2007; 100: 821-4.

[9] Mills JA, Michel BA, Bloch DA, et al. The American College of Rheumatology 1990 criteria for the classification of HenochSchönlein purpura. Arthritis Rheum 1990; 33: 1114-21.

[10] Blanco R, Martínez-Taboada VM, Rodríguez-Valverde V, GarcíaFuentes M, González-Gay MA. Henoch-Schönlein purpura in adulthood and childhood: two different expressions of the same syndrome. Arthritis Rheum 1997; 40: 859-64.

[11] Tancrede-Bohin E, Ochonisky S, Vignon-Pennamen MD, Flaguel B, Morel P, Rybojad M. Schönlein-Henoch purpura in adult patients. Predictive factors for IgA glomerulonephritis in a retrospective study of 57 cases. Arch Dermatol 1997; 133: 438-42.

[12] García-Porrúa C, Calviño MC, Llorca J, Couselo JM, GonzálezGay MA. Henoch-Schönlein purpura in children and adults: clinical differences in a defined population. Semin Arthritis Rheum 2002; 32: 149-56.

[13] Diehl MP, Harrington T, Olenginski T. Elderly-onset HenochSchönlein purpura: a case series and review of the literature. J Am Geriatr Soc 2008; 56: 2157-9. 
[14] Zurada JM, Ward KM, Grossman ME. Henoch-Schönlein purpura associated with malignancy in adults. J Am Acad Dermatol 2006; 55: S65-70.

[15] Ozen S, Pistorio A, Iusan SM, et al. EULAR/PRINTO/PRES criteria for Henoch-Schönlein purpura, childhood polyarteritis nodosa, childhood Wegener granulomatosis and childhood Takayasu arteritis: Ankara 2008. Part II: Final classification criteria. Ann Rheum Dis 2010; 69: 798-806.

[16] Izaki S, Goto Y, Kaburagi Y, Kitamura K, Nomaguchi H. Antibody production to heat shock protein with $\mathrm{Mr} 65 \mathrm{kD}$ (HSP65) in cutaneous inflammation: a possible relation to focal infection. Acta Otolaryngol (Stockh) 1996; Suppl 523: 197-200.

[17] Mitsui H, Shibagaki N, Kawamura T, Matsue H, Shimada S. A clinical study of Henoch-Schönlein Purpura associated with malignancy. J Eur Acad Dermatol Venereol. 2009; 23: 394-401.

[18] Elbert EC. Gastrointestinal manifestations of Henoch-Schonlein purpura. Dig Dis Sci 2008; 53: 2011-9.

[19] Chen XL, Tian H, Li JZ, et al. Paroxysmal drastic abdominal pain with tardive cutaneous lesions presenting in Henoch-Schönlein purpura. World J Gastroenterol 2012; 18: 1991-5.

[20] Matayoshi T, Omi T, Sakai N, Kawana S. Clinical significance of blood coagulation factor XIII activity in adult Henoch-Schönlein purpura. J Nippon Med Sch 2013; 80: 268-78.

[21] Smith G. Management of Henoch-Schönlein purpura. Pediatr Child Health 2008; 18: 358-63.
[22] Chen KR, Carlson JA. Clinical approach to cutaneous vasculitis Am J Clin Dermatol 2008; 9: 71-92.

[23] Bech AP, Reichert LJ, Cohen-Tervaert JW. Dapsone for the treatment of chronic IgA vasculitis (Henoch-Schonlein). Neth J Med 2013; 71;220-1.

[24] Calvo-Río V, Loricera J, Mata C, et al. Henoch-Schönlein purpura in northern Spain: clinical spectrum of the disease in 417 patients from a single center. Medicine (Baltimore) 2014; 93: 106-13.

[25] Fretzayas A, Sionti I, Moustaki M, Nicolaidou P. Clinical impact of altered immunoglobulin levels in Henoch-Schönlein purpura. Pediatr Int 2009; 51: 381-4.

[26] Byun JW, Song HJ, Kim L, Shin JH, Choi GS. Predictive factors of relapse in adult with Henoch-Schönlein purpura. Am J Dermatopathol 2012; 34: 139-44.

[27] Poterucha TJ, Wetter DA, Gibson LE Camilleri MJ, Lohse CM Histopathology and correlates of sysytemic disease in adult Henoch-Schönlein purpura: A retrospective study of microscopic and clinical findings in 68 patients at Mayo Clinic. J Am Acad Dermatol 2013; 68: 420-4.

[28] Katsuoka K, Kawakami T, Ishiguro N, et al. Guidelines for management of vasculitis and vasculopathy (in Japanese). Nippikaishi 2008; 118: 2095-187.

[29] Ozaki S, Ando M, Isobe M, et al. Guideline for management of vasculitis syndrome (JCS 2008). Japanese Circulation Society. Circ J 2011; 75: 474-503.

(C) Hitomi et al.; Licensee Bentham Open.

This is an open access article licensed under the terms of the Creative Commons Attribution Non-Commercial License (http://creativecommons.org/licenses/by-nc/3.0/) which permits unrestricted, non-commercial use, distribution and reproduction in any medium, provided the work is properly cited. 